\title{
Notas para una poética de la Educación
}

\author{
Maximiliano Valerio López \\ maximilianolopez@vm.uff.br \\ Universidade Federal Fluminense (UFF) - Brasil
}

Resumen: Las páginas que siguen constituyen un ejercicio de aproximación a lo que podríamos denominar una poética de la educación. No tienen otra pretensión que la de presentar algunos conceptos que podrían abrir el camino de una reflexión futura. Como se verá en el transcurso del trabajo, al hablar aquí de poética no se hace referencia a un género de la literatura, sino a una experiencia del lenguaje que puede iluminar de algún modo la forma en que concebimos el acto educativo. 


\section{Una distancia íntima}

"Aquello que hay en mí, que no soy yo, y que busco.

Aquello que hay en mí, y que a veces pienso que

también soy yo, y no encuentro.

Aquello que aparece porque sí, brilla un instante y luego

se va por años

y años.

Aquello que yo también olvido.

Aquello

próximo al amor, que no es exactamente amos;

que podría confundirse con la libertad,

con la verdad

con la absoluta identidad del ser

_ y que no puede, sin embargo, ser contenido en palabras

pensado en conceptos

no puede siquiera ser recordado como es”.

(...)

(Mario Levrero, 2009: 11)

Nacemos dos veces, una cuando nos nace el cuerpo, otra, cuando adquirimos idea de nosotros mismos. Este descompás determina nuestro modo de ser. Si como lo definiera Aristóteles, somos un zoon logon echon, un viviente dotados de palabra, no lo somos al momento de nacer, sino después, cuando conseguimos nombrarnos y nombrar el mundo que nos rodea. Nacemos, por decirlo así, separados de nuestra naturaleza. Fuera del lenguaje, fuera de la ley, fuera de la historia, es decir, fuera de la cultura. Fuera de nosotros mismos.

Como lo refiere Lyotard, "No soy yo quien nazco, quien es alumbrado, (enfanté). Yo mismo naceré después, precisamente, al salir de la infancia (enfance)" (LYOTARD, 1997: 44-45). Por eso nacemos para otros antes de hacerlo para nosotros mismos. Y por no haber estado presentes en nuestro nacimiento, por haber sido originalmente para otros, por haber sido otros los que 
estuvieron en nuestro origen, tendremos por siempre la alteridad como lugar de nacimiento. Al interrogarnos por nuestro origen seremos lanzados, una y otra vez, en dirección a una otredad que constituye para nosotros lo más íntimo.

Esa distancia que separa el cuerpo, que nació antes y que, por tanto, siendo nuestro aun no era de nosotros, de ese nudo de lenguaje y memoria que somos ahora, será el objeto de nuestro estudio en las páginas que siguen. Dicha falla temporal no se supera con el ingreso en la madurez, sino que nos acompaña durante toda la vida y funda la experiencia humana: su forma particular de ser tiempo y lenguaje. Sus consecuencias son inmensas y difíciles de determinar.

Si esta breve reflexión tiene un sesgo educativo, es precisamente porque, no es, sino frente a esta fractura temporal, que la educación se yergue y justifica. Aquello que llamamos educación no es otra cosa que la manera en que lidiamos con esa distancia íntima que separa a la humanidad de sí misma.

\section{La oralidad}

La voz, no el silencio,
es la desnudez de las palabras.

(Hugo Mujica, 2006: 452)

La oralidad ha sido entendida, en la tradición occidental, como el reverso o el negativo de la escritura. De ese modo "oral" ha significado apenas, lo que no es escrito; una "falta", característica de pueblos primitivos e individuos analfabetos. Pero la ausencia de escritura no dice absolutamente nada respecto a la especificidad de lo oral. Hoy en día, gracias a los estudios de autores como Paul Zumthor y Henri Meschonnic es posible entender la oralidad de modo positivo, ya no como una falta, sino como la forma en que el cuerpo se hace presente en el lenguaje, tanto en su manifestación escrita como vocal. A través de la voz, el cuerpo insiste en el lenguaje.

La voz es cuerpo, temblor físico, vibración sensible: 1lanto, grito, risa, suspiro. La voz es cuerpo: por eso tiembla y se adelgaza, se inflama, se corta, se cansa. Constituye la parte del lenguaje que escapa a la representación. Es necesario distinguir el cuerpo, de la imagen que nos hacemos de 
él. Lo que se manifiesta en la voz es un conjunto de afecciones, múltiple y heterogéneo, anterior a toda representación. No es un organismo, es decir, un sistema constituido por órganos y funciones, puesto ante nuestra mirada como objeto de conocimiento. No es el cuerpo-objeto de la medicina, ni el cuerpo-máquina de la física. El cuerpo que se manifiesta en la voz no es el cuerpo que nombramos, sino justamente lo que escapa al nombre, a cualquier tentativa de objetivación.

Por esa razón este cuerpo que vive en la voz es anterior a cualquier conciencia individual, anterior a ese "yo", que, como lo refiere Lyotard, nacerá después, con la capacidad de nombrar. Por eso, en sentido estricto, sería exagerado decir que ese cuerpo, que nació antes del lenguaje, sea "mi cuerpo". Lo que se manifiesta en la voz es afección pura. No es mi cuerpo, en el sentido de un objeto que yo pueda pensar y nombrar, sino justamente, lo que escapa a mi dominio, lo que no alcanza el concepto. El cuerpo que la voz trae al lenguaje es una superficie sensible, una pura afección.

Esta afección es continua, es decir no reconoce fronteras precisas entre eso que al pensar delimitamos como "nuestro cuerpo" y las circunstancias que lo afectan. En la voz vive un clima, hecho de las singularidades que se conjugan en un momento particular: un tono físico, una temperatura ambiente, una luminosidad, un aroma: la manera en que las personas se afectan unas a otras y son afectadas por un determinado entorno. Por eso la voz le pertenece a la relación $\mathrm{y}$ no a los individuos, $\mathrm{y}$ al modo en que esa relación se determina en un momento y en un ambiente particular. No hablamos con la misma voz a un amigo, a nuestra esposa o al señor que atiende el kiosco de revistas. A nuestros amigos, no les hablamos con la misma voz en la mañana que en la noche. No comenzamos una relación amorosa con la misma voz que la terminamos. La voz es afecto y circunstancia.

\section{El ritmo}

Esa relación y esa circunstancia que fluye en la voz se determina temporalmente a través de un ritmo. Cada uno de nosotros al hablar despliega una forma-afecto, en la cual los oyentes participan. Si el concepto es básicamente “distinción” (principio de no contradicción: o esto o aquello) la voz en la que este se sostiene es, fundamentalmente, "participación". 
En un bellísimo artículo de 1951 titulado La noción de “ritmo" en su expresión lingüística, Benveniste emprende, a partir de un estudio filológico, una re-conceptualización de la noción de ritmo, digna de destaque. Según una definición dominante, que Benveniste se propone

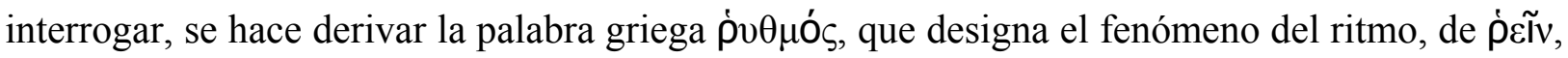
que tiene el sentido de "fluir", habiendo sido tomado el significado de la palabra ritmo, según se dice, del movimiento regular de las olas. No hay dificultades morfológicas, nos dice Benveniste,

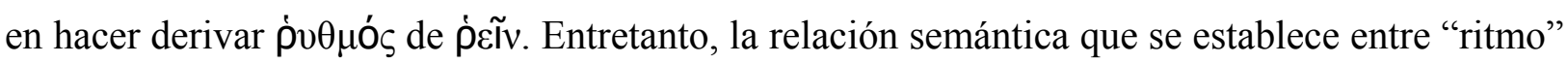
y "fluir", por medio del movimiento regular de las olas no resiste el más mínimo examen, dado que el mar no fluye, fluyen los ríos, y lo hacen de modo continuo. De hecho, jamás se encuentra

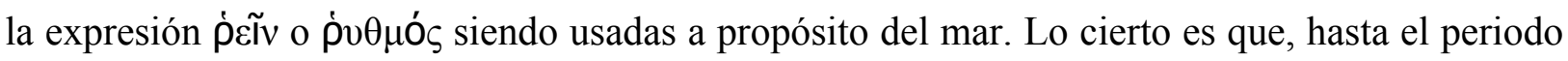
clásico, más precisamente hasta Platón, la palabra ritmo, no adquiere el sentido actual de movimiento reglado y cadencioso, sucesión de tiempos fuertes y tiempos débiles, que se volvió dominante entre nosotros. Antes del periodo clásico este sentido está ausente. En los poemas homéricos, en los escritores jónicos, en la poesía lírica y trágica, en la prosa ática y sobre todo en los filósofos anteriores al periodo clásico, la palabra ritmo era utilizada exclusivamente con el sentido de forma: configuración, orden, posición, carácter, actitud, condición momentánea, estado de ánimo, modalidad, marca distintiva, disposición anímica, etc. No obstante, advierte Benveniste, para la idea de forma existían en griego otras expresiones como $\sigma \chi \eta \mu \alpha, \mu о p \Phi \eta ́$,

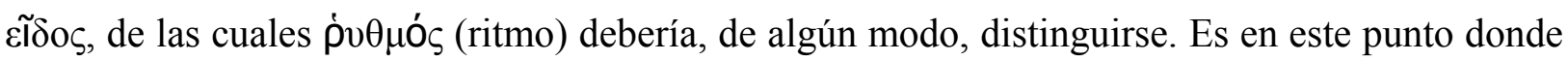
la investigación de Benveniste se muestra sutil y aguda. Otras expresiones griegas como $\sigma \chi \eta \mu \alpha$ (esquema) dan cuenta de la forma fija, ya realizada, puesta de algún modo como un objeto, mientras que, el vocablo jo $\theta \mu$ ós (ritmo), según los contextos en que aparece, designa la forma en el instante en que es asumida por aquello que es movedizo, móvil, fluido, forma de aquello que no tiene una consistencia orgánica. Conviniendo entonces al pattern de un elemento fluido, a una letra arbitrariamente modelada, a la disposición particular del carácter o del humor, es decir, a las formas improvisadas, momentáneas, modificables, fluyentes. De hecho, para Demócrito (quien pensaba que, al ser todo producido por los átomos, sólo el arreglo diferente producía la diferencia de las formas y los objetos), "ritmo", significaba literalmente, "manera particular de fluir", siendo entonces el término más apropiado para describir "disposiciones” o "configuraciones" sin fijación ni necesidad natural, resultantes de un arreglo siempre sujeto a 
mudanzas, aplicándose así a lo que fluye de forma continua. No es sino hasta mediados del siglo $\mathrm{V}$ a.c. que esta noción es sometida a la idea de orden, movimiento reglado, numerable, medible, cadencioso, discontinuo, propia de nuestros días.

Lo que se manifiesta en la voz es, precisamente, una forma fluyente, un ritmo. Durante los minutos que alguien canta, explica un asunto o nos cuenta una historia, nos olvidamos de nosotros mismos y participamos de una forma-fuerza que inunda todo el ambiente. Por algunos instantes habitamos una forma, un timbre, una melodía, una coloración particular. La voz que ante nosotros se despliega no es sólo un sonido a ser escuchado, sino que configura, al mismo tiempo, la propia escucha. El ritmo es también la propia escucha. Paul Zumthor ha recogido esta "forma moviente" en la idea de performance: un dinamismo formalizado, que no es regido por una regla, sino que es la propia regla. Una regla recreada a cada instante, existiendo sólo en la pasión de cada persona que, a cada instante, adhiere a ella en un encuentro luminoso. Dicha forma, rige simultáneamente el tiempo, el lugar, la finalidad de la transmisión, la acción del locutor y, en amplia medida, la respuesta del público (ZUMTHOR, 2007: 29-30). La voz es afecto, circunstancia y forma fluyente.

\section{El habla}

En el habla humana se confunden dos dimensiones que difieren por naturaleza: de un lado la voz (cuerpo, afecto, circunstancia, ritmo, forma fluyente), del otro, la lengua (estructura gramatical constituida por elementos lingüísticos y reglas de composición). La primera es singular, corporal, continua; la segunda, es general, simbólica, discontinua. Entre la voz y la lengua, lo sensible y lo inteligible, lo particular y lo general, la tierra y el cielo, lo humano y lo divino, centellea, frágil y efímera, el habla humana.

En el habla se unen, fugazmente, una voz (inhumana, íntima, pero inalcanzable) y una lengua (siempre ajena e indiferente). En la voz viven afectos remotos, inefables, que ya perdieron la memoria. Dolores innombrables que no recuerdan por qué son dolores. En el habla hay, además de una voz, una lengua, que vive por sí misma y no nos necesita. La palabra amor, duerme indiferente en el diccionario y dice cualquier amor, no el mío. Entre la imposibilidad de nombrar 
el cuerpo que vive en la voz y la imposibilidad de animar palabras insensibles se abre la posibilidad de decir, la potencia de decir, la experiencia de decir.

Entre la voz y la lengua no hay continuidad ni pasaje. Entre una y otra se abre un espacio vacío, un abismo al cual nos vemos arrojados cada vez que nos proponemos decir verdaderamente algo, pues la coherencia última es musical: nupcias imposibles entre la viva voz y la estructura inerte de la lengua. Hacer la experiencia de ese vacío, de esa herida abierta en el corazón del idioma es hacer la más radical experiencia del lenguaje: la experiencia poética.

\section{Experimentum linguae}

Holderling denominó esta distancia "alejamiento categórico", Giorgio Agamben ha designado con el nombre de experimentum linguae la experiencia de este abismo. Esta distancia abierta entre la voz y la lengua, constituye la condición del habla humana. Lo que nos diferencia de los animales no es el hecho de poseer una lengua, ambos la poseemos, sino el hecho de tener que buscar las palabras, es decir, el hecho de no estar naturalmente en el lenguaje. Cada vez que nos disponemos a hablar experimentamos ese vacío, esa distancia, que separa nuestra voz animal, de una lengua convencional, artificial, impropia. Lo que nos separa de los animales es que para nosotros existe la in-fancia, es decir, la distancia entre la voz y la lengua. Entre una y otra dimensión, radicalmente heterogéneas se despliega la potencia de hablar, la experiencia creadora de la palabra: la experiencia poietica.

Se trata de la más extrema y radical experiencia del lenguaje: una imposibilidad de hablar a partir de una lengua. La impotencia de no tener una lengua natural, como el trinar de los pájaros o el ladrido de los perros. Impotencia que coincide, sin embargo, con la mayor de las potencias. Imposibilidad que constituye, al mismo tiempo, el corazón mismo de toda posibilidad. Para quienes poseemos una infancia y por tanto, nos vemos obligados a procurar una y otra vez las palabras la condición natural es, de algún modo, la de hablar sin saber hablar.

Esto es lo que Heidegger vio en la obra de Hölderlin. Este último es el poeta de los poetas, el poeta de lo poético, pues canta el lugar de donde nacen las palabras. Ese lugar es el espacio vacío que se abre entre la tierra y el cielo, entre lo humano y lo divino. Ese es el lugar que según el poeta alemán ocupan las figuras de Edipo. Rechazado por los hombres y por los dioses, el 
héroe de la célebre tragedia de Sófocles queda suspendido en un espacio vacío, entre lo humano y lo divino. Ni revelación divina, ni técnica humana, lo poético, la experiencia límite del lenguaje, se yergue entre la imposibilidad de ingresar en uno y otro dominio. El poeta es un infante que, experimentado la mayor imposibilidad, la mayor intemperie. Ha hecho la experiencia más humana, la más solitaria, habitando el lugar donde nacen las palabras.

Por eso Heidegger ha dicho:

"La poesía no es sólo un adorno que acompaña la existencia humana, ni una pasajera exaltación, ni un acaloramiento y diversión. La poesía es el fundamento que soporta la historia, y por ello no es tampoco una manifestación de la cultura, y menos aún la mera ‘expresión' del 'alma de la cultura"”.

"La poesía no toma el lenguaje como un material ya existente, sino que la poesía misma hace posible el lenguaje. La poesía es el lenguaje primitivo de un pueblo histórico... Es preciso entender la esencia del lenguaje por la esencia de la poesía”.

(HEIDEGGER, 1936: Hölderlin y la esencia de la poesía)

\section{Lo poético}

Es preciso entender el lenguaje a través de la poesía y no al contrario, pues la poesía no es un adorno, un agregado. Hablar poéticamente no es hablar bonito, sino simplemente hablar humanamente. Es decir, hablar desde esa fisura que nos impide estar desde siempre unidos a nuestra naturaleza. No se puede hablar sino poéticamente, es decir, fuera de la naturaleza, pero también, fuera de la lengua. Sabiendo que, lo verdaderamente dicho, no está en las palabras, ni fuera de ellas. Sabiendo que lo que es importante decir, la verdad de lo que decimos, desborda los diques del diccionario. Hablar humanamente es adentrarse en el lenguaje, sin la protección de una gramática: hablar siempre sin saber hablar. 
Aprender a hablar, ingresar en el universo de lo humano, no pasa por alcanzar una destreza, una cierta competencia lingüística, sino por adquirir el temple, el tono que nos permita soportar la desnudez de la propia voz.

\section{Referencias bibliográficas}

MUJICA, Hugo. Poesía completa. Buenos Aires: Seix Barral, 2006.

LEVRERO, Mario. El discurso vacío. Barcelona: Debolsillo, 2009.

MESCHONNIC, Henri. La poética como crítica del sentido. Buenos Aires: Marmos-Izquierdo Editores, 2007.

ZUMTHOR, Paul. Performance, recepção, leitura. São Paulo: Cosac Naify, 2007.

AGAMBEN, Giorgio. Infância e História: destruição da experiência e origem da história. Belo Horizonte: Editora UFMG, 2005.

HEIDEGGER, Martin. Hölderlin y la esencia de la poesía. Sitio Heidegger en castellano. http://www.heideggeriana.com.ar/textos/holderlin_esencia-poesia.htm : 14 de diciembre de 2009.

HOLDERLIN, Friedrich. Observações sobre Édipo; Observações sobre Antígona. Rio de Janeiro: Jorge Zahar Ed., 2008. 